\title{
Benefits of retailer-supplier partnership initiatives under time-varying demand: a comparative analytical study
}

\author{
Devendra Choudhary, Ravi Shankar, Prasanta K. Dey, Harish Chaudhary \& Lakshman S. Thakur
}

\section{Introduction}

Simchi-Levi et al. (2008) propose the view that retailer-supplier partnership (RSP) is a continuum. At the one end of this continuum is information sharing (IS), which helps the supplier plan more efficiently, and at the other end is a consignment scheme, where the supplier completely manages and owns the inventory until the retailer sells or uses it. Thus, under RSP, two or more chain partners work together to create competitive advantage through sharing of information (Lee, So, and Tang 2000; Sahin and Robinsonjr 2005), collaboration (Barratt and Oliveira 2001; Barratt 2004) and sharing of benefits (Cachon 1999).

It is a well-known fact that sharing of information between suppliers and retailers improves the supply chain competitiveness. Retailer-managed inventory with IS, which we will call RMI, is the first level of RSP to exploit the advantages of IS. Under RMI, the retailers manage and own the inventory, but provide the suppliers an access to information related to its real-time inventory levels, planned orders and demand forecasts. This IS mostly produces benefits for the upstream suppliers (Gavirneni, Kapuscinski, and Tayur 1999; Lee, So, and Tang 2000; Sahin and Robinsonjr 2005). For a fair distribution of the benefits obtained by IS between the suppliers and retailers and to motivate the retailers to do so, there is an RSP practice in which the inventory is still managed by the retailers while owned by the upstream suppliers. Thus, in retailer-managed consignment inventory ( $\mathrm{RMCl})$, the suppliers retain the ownership of the inventory and get paid from the retailers based on actual units sold or used (Gümus, Jewkes, and Bookbinder 2008). It is expected that the retailers would gain by moving from RMI to $\mathrm{RMCl}$ because they do not incur the opportunity cost of carrying inventory. However, how shift in inventory ownership would benefit the suppliers and system as a whole is less clear (Simchi-Levi et al. 2008). Even more, in both RMI and RMCl, the suppliers and retailers act independently. These RSP initiatives may not obtain the benefits of the centralised system due to independent decision-making and focus on local optimisation of each partner without considering the impact of its decisions on the performance of others (Toktaş-Palut and Ülengin 2011). Due to this fact as well as the increased cost pressure and more demanding customers have forced companies to move ahead of IS and/or shift in inventory ownership to improve supply chain competitiveness with new form of retailer-supplier collaborative initiatives. One of such collaborative relationship is vendor-managed inventory (VMI), which enables shift in decision-making power from downstream retailers to upstream suppliers. In other words, under VMI, the suppliers take responsibility of managing inventory at the retailers. They decide upon replenishment quantities and timings in parallel with their own inventory decisions based on the retailers' inventory position and demand information. In this case, the retailers do not place orders but own the inventory as soon as it arrives in their warehouses (Bookbinder, Gümüş, and Jewkes 2010; Borade, Kannan, and Bansod 2013).

Prior studies show that the shift in decision-making power is more attractive to the suppliers. However, it is less clear as to why retailers would be ready to switch from $\mathrm{RMCl}$ to VMI. In order to facilitate a win-win situation under shift in decision-making power, two other important RSP initiatives proposed in the literature are vendor-managed consignment inventory ( $\mathrm{VMCl}$ ) and collaborative planning, forecasting and replenishment (CPFR). $\mathrm{VMCl}$ is characterised by a partnership contract in which the inventory at the retailers is both managed and owned by the suppliers. CPFR, on the other hand, requires all the partners of a supply chain to jointly develop demand forecasts and manage through promotions. The main characteristics of these RSP initiatives are summarised in Table 1. 
Table 1. Characteristics of retailer-supplier partnership initiatives.

\begin{tabular}{|c|c|c|c|c|c|}
\hline \multirow[b]{2}{*}{ Criteria } & \multicolumn{5}{|c|}{ RSP initiatives } \\
\hline & RMI & RMCI & VMI & VMCI & CPFR \\
\hline Ordering decision maker & $R$ & $\mathrm{R}$ & s & S & S \\
\hline Bearer of ordering cost & $R$ & $\mathrm{R}$ & s & s & S \\
\hline Bearer of opportunity cost of the retailer's stock & $R$ & s & $R$ & s & R \\
\hline Information sharing & Y & Y & Y & Y & $\mathrm{Y}$ \\
\hline Requirement of agreement/contract & N & $\mathrm{N}$ & $\mathrm{Y}$ & Y & $\mathrm{Y}$ \\
\hline Joint forecasts & $\mathrm{N}$ & $\mathrm{N}$ & N & N & Y \\
\hline Demand management & $\mathrm{N}$ & $\mathrm{N}$ & $\mathrm{N}$ & N & $\mathrm{Y}$ \\
\hline Supplier's concern to the retailer & L & M & $\mathrm{H}$ & $\mathrm{H}$ & $\mathrm{H}$ \\
\hline Retailer's concern to the supplier & $\mathrm{H}$ & $\mathrm{H}$ & L & M & $\mathrm{H}$ \\
\hline
\end{tabular}

R: the retailer, S: the supplier, Y: yes, N: no, L: low, M: medium, H: high

Source: Simchi-Levi et al. (2008), Gümüş, Jewkes, and Bookbinder (2008), Tyan and Wee (2003).

In recent years, there has been growing interest in implementing advanced RSP initiatives in several supply chains after successful execution by manufacturers such as Proctor \& Gamble and Kimberly-Clark and big retailers like WalMart. The inclination toward advanced RSP initiatives is due to the fact that there are benefits to the whole chain in terms of cost and inventory reductions as well as improved service levels. However, the extent and intensity of competitive advantage gained from RSP initiative depends on business environment and varies from company to company. Also, in practice, switching to advanced RSP initiative beyond IS leads to greater implementation difficulties and increase in operational costs. Thereby, benefits of an advanced RSP initiative should be higher than the cost of investing in that particular initiative. Prior researchers also emphasise that allocation of benefits across supply chain partners is not equitable. In other words, it is not necessary that an RSP initiative can be equally profitable to all partners. Some partners can obtain more benefits, whereas others may suffer losses (Sahin and Robinsonjr 2005; Gümüs, Jewkes, and Bookbinder 2008; Yao and Dresner 2008; Bookbinder, Gümüş, and Jewkes 2010). In such a situation, it is also possible that worse-off partners may not be interested in switching beyond IS. To avoid this kind of situation, it is necessary to find a method to influence the partners' decision and better share the benefits. Cachon (1999) emphasises that suppliers and retailers should share the benefits to obtain channel coordination using VMI in a two-echelon supply chain.

This study aims to determine the value of RSP initiative beyond IS under time-varying deterministic demand conditions. For a specific business environment, selecting the right kind of RSP initiative beyond IS or finding the best method to equally share benefits among partners is not simple. One needs to consider the business context of the whole chain as well as impact of an RSP initiative on the supply chain performance measures. For this purpose, we use integer linear programming models to quantify the benefits that can be accrued by a retailer, a supplier and system as a whole from $\mathrm{RMCl}$ and VMI with that of retailer-managed inventory with IS. Thus, the RMI is considered as the benchmark to show under what business environment $\mathrm{RMCl}$ or VMI would provide benefits in terms of cost and inventory reductions for a retailer, a supplier and the system as a whole. More precisely, this study addresses the following questions.

i. As compared with RMI, when would RMCl or VMI result in a win-win situation for both the supplier and the retailer?

ii. When would VMI result in a potentially efficient system (i.e. one partner is better-off while the other is worse-off, and system-wide savings is achieved using VMI) and how could it be turned into an efficient one (i.e. both the partners are better-off as compared with RMI)?

iii. How does $\mathrm{RMCl}$ or VMI affect replenishment decisions compared to RMI under different business scenarios?

iv. How do system parameters affect the supply chain performance measures such as reduction in costs and inventory levels as well as increase in replenishment frequencies at the retailer?

The next section provides research gaps and novelty of this study based on a brief literature review. Problem description, mathematical models used as well as research findings and managerial insights derived from numerical 
experimentations are discussed in the subsequent sections. Finally, paper is concluded along with limitations and directions for future research.

\section{Literature review}

In this section, we review the literature that applies analytical modelling approaches to quantify the benefits of RSP initiatives. The classification of analytical models proposed in the literature for RSP initiatives based on demand type and number of partners at the downstream echelon is summarised in Figure 1.

Figure 1. Classification of analytical models proposed for RSP initiatives.

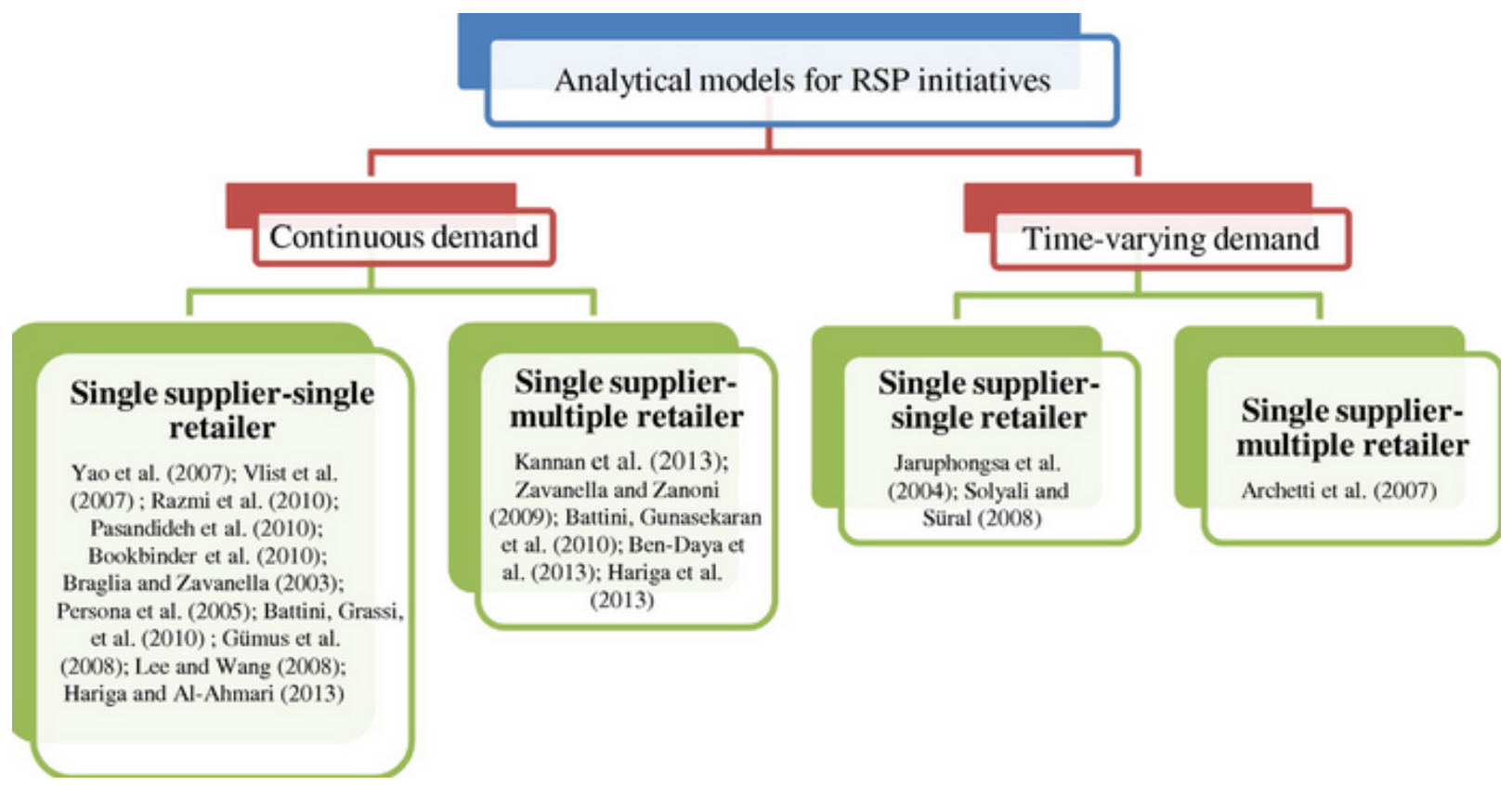

The IS is an important business partnership that was initiated in the mid1980s to deal with competition, slow growth and reduced margins in the apparel industry to reduce lead time and inventory cost (Giunipero et al. 2001). A correlation analysis carried out by Giunipero et al. (2001) indicates that firms having more advanced IS programmes perceived fewer problems than those with less advanced programmes. Further, a partial relationship was found between IS and improved financial performance.

Yao, Evers, and Dresner (2007) develop an EOQ-based analytical model to explore how a few supply chain parameters affect the cost savings through VMI as compared to no-VMI. Results of this study show that cost savings depend upon the ratio of ordering costs and inventory holding charges of the partners. They demonstrate that benefits are higher when retailer's ordering cost reduces using VMI. However, at some extremes, the total benefits of VMI may be negative. Later, van der Vlist, Kuik, and Verheijen (2007) extend the model of Yao, Evers, and Dresner (2007) considering cost of shipments from the supplier to the retailer and conclude that under VMI shipment sizes from supplier to retailer increase, inventory at the supplier goes down, but inventory at the retailer goes up. Yao and Dresner (2008) compares the benefits of IS, continuous replenishment programme (CRP) and VMI for both the retailer and supplier considering order-up-to level periodic review system assuming first-order autoregressive stochastic demand process. Through analytical models and numerical analysis, they show that IS, CRP and VMI brings varying benefits in terms of inventory cost savings to the partners. Moreover, the benefits are not consistently distributed between them and depend on replenishment frequency and inventory holding costs. Their analysis suggests that VMI reduces both the supplier's cycle inventory and safety stock as compared to CRP. Therefore, the 
upstream supplier receives relatively greater benefits than the downstream retailer using VMI. Razmi, Rad, and Sangari (2010) and Pasandideh, Niaki, and Nia (2010) propose EOQ-based mathematical model for comparing traditional system with VMI system based on minimisation of total cost as the performance measure of two partners involved in VMI contract. Lee and Ren (2011) study VMI in a global environment with exchange rate uncertainty. The study reveals that supply chain total cost always decreases under VMI and the reduction of the supply chain total cost is larger under exchange rate uncertainty than the case of no exchange rate uncertainty.

Bookbinder, Gümüş, and Jewkes (2010) derive interesting inequalities using EOQ-based analytical models and by comparing traditional supply chain, $\mathrm{VMI}$ and centralised system. This study considers that cost parameters may vary between the three frameworks and each framework may cause a different partner to be responsible for particular expenses. They also incorporate order issuing efficiency of the supplier under VMI system based on realistic assumption that the supplier may incur less cost as compared to when the retailer orders on his/her own under traditional system; because, the supplier is placing orders from his/her own organisation under VMI. They show that VMI may not be beneficial to both the partners as compared to traditional system in many situations under a continuous deterministic demand. However, under VMI, both the partners become better-off when inventory holding cost ratio of the supplier to retailer is greater than the supplier's efficiency factor. Later, Kannan et al. (2013) extend the work of Bookbinder, Gümüş, and Jewkes (2010) for one supplier, multiple retailers and multiple product situations.

Corbett (2001) provides a framework to point out how supply chain incentives should be realigned to overcome existing information asymmetries. In addition, a theoretical analysis and a case study suggest that consignment stock (CS) helps to reduce cycle stock by providing the supplier with an additional incentive to decrease batch size, but simultaneously give the buyer an incentive to increase safety stock by exaggerating backorder costs. Braglia and Zavanella (2003) assess cost performance of the CS policy compared to the case with no partnership. Valentini and Zavanella (2003) show that, under CS policy, service-level and shipment flexibility depend on the minimum and maximum, (s, S), levels agreed on between the two partners. Zavanella and Zanoni (2009) extend the work of Braglia and Zavanella (2003) for single-supplier multi-retailer system. Zanoni, Jaber, and Zavanella (2012) study a VMCI framework considering a situation in which a supplier experiences a learning effect during production process. The study reveals that both learning rate and length of interruption period over which total forgetting occurs have a significant impact on the total cost and shipment schedule. Persona, Grassi, and Catena (2005) propose an analytical formulation of CS policy with obsolescence. Battini, Grassi, et al. (2010) extend the work of Persona et al. (2005) in an industrial environment with demand variability, stock-out risk and limited warehouses space. Battini, Gunasekaran, et al. (2010) enrich the work of Battini, Grassi, et al. (2010) by evaluating economical and logistic benefits of CS policy implementation in a single vendor-multiple buyer system. They show that CS policy is beneficial to the system as a whole under stochastic demand, risk of obsolescence and space constraint. Fang, So, and Wang (2008) develop a mathematical model to analyse the performance of $\mathrm{VMCl}$ programme for a contract manufacturer who procures multiple components from independent suppliers to produce an assemble-to-order customised product for a client. Using a game-theoretical framework, they determine the manufacturer's pricing policy for suppliers' consignment inventories that maximises his expected profit.

Gümus, Jewkes, and Bookbinder (2008) derive interesting inequalities by comparing traditional supply chain with both $\mathrm{RMCl}$ and $\mathrm{VMCl}$ systems under continuous deterministic demand. They show that the retailer is always betteroff under $\mathrm{RMCl}$ compared to traditional system. Moreover, under $\mathrm{RMCl}$, as compared with no partnership, cost savings for the supplier as well as system as a whole can be achieved if the supplier prefers a fewer shipments and ratio of supplier's shipment release cost to retailer's ordering plus shipment receiving cost is significantly greater than inventory holding cost ratio between them. Lee and Wang (2008) propose a model to analyse the impact of available consignee's warehouse space capacity constraint on the manufacturer's total cost, production batch and replenishment lot-sizes. Li, Zhu, and Huang (2009) propose the cooperative game models to explore the coordination mechanism for decentralised supply chain under the consignment contract with revenue sharing. Ru and Wang (2010) consider a single period supply chain model where a supplier contracts with a retailer when the demand for 
the product is price-sensitive and uncertain. They study and compare $\mathrm{RMCl}$ and $\mathrm{VMCl}$ programmes using gametheoretic approach. The results of their study indicate that both parties are better-off when supplier takes the inventory decision rather than the retailer.

Hariga and Al-Ahmari (2013) propose an integrated retail space allocation and inventory model under $\mathrm{VMCl}$ for a single item with a stock-dependent demand. Through experimental results, they show that $\mathrm{VMCl}$ is always beneficial to the retailer in all scenarios except for low-inventory capital cost and low demand. Moreover, both partners get more benefits under $\mathrm{VMCl}$ compared to traditional way of doing business when the retailer provides a flexible display capacity. Ben-Daya et al. (2013) find that shipment sizes from a supplier to retailers decrease under VMCI. Moreover, cost saving under $\mathrm{VMCl}$ is more when supplier has flexible capacity and retailers have lower setup costs and significant order costs. Hariga et al. (2013) consider a supply chain where a single supplier manages multiple retailers' stock under a VMI contract in which retailers specify their maximum allowed inventory levels. They propose a mixed integer non-linear model that allows unequal replenishment intervals. Then, they apply cost efficient heuristic to solve the model and observe that cost savings realised from VMI are greater in cases of increased variability in retailers' demand and cost parameters.

Achabal et al. (2000) describe how a decision support system can be implemented under VMI regime for integrating market forecasting and inventory management components. Aviv (2002) examines a two-level supply chain consisting of a retailer and a supplier considering three configurations: cooperative without sharing observation of market signal, VMI without sharing market signals, and collaborative forecasting and replenishment partnership with demand IS. Choi, Dai, and Song (2004) analyse a decentralised two-party capacitated supply chain consisting of one manufacturer and one supplier in a VMI environment. The study finds that supplier's service level is insufficient for the manufacturer to warrant the desired service level at the customer end. Further, the study demonstrates that the method by which the supplier achieves her service level to the manufacturer also affects customer service level.

Dong and Xu (2002) examine the optimal behaviour of a retailer and a supplier before and after VMI for a pricedependent linear demand function. They observe that profit is higher under VMI than that prior to VMI when there is significant mismatch in the ordering and holding cost ratios of the partners. Xu and Leung (2009) propose an analytical model for the two-party vendor managed channel with space restriction to determine the inventory policy with objective of optimising system net profit. Factors such as shelf-space capacity, demand pattern, logistics characteristics and disparity between holding cost of the warehouse and the retail store are also investigated. Chen and Wei (2012) propose a calculus-based formulation combined with dynamic programming solution techniques for VMI system for deteriorating goods. They compare RMI and VMI using three business agreements, namely, priceonly contract, revenue-sharing contract, and revenue-sharing plus linear rebate and side-payment contract. Their study reveals that VMI with revenue-sharing plus linear rebate and side-payment contract obtains low retail prices.

Fry, Kapuscinski, and Olsen (2001) model VMI operating under an order-up-to level contract, or (z, Z) contract, in a stochastic setting. The optimal behaviours of both the supplier and retailer are examined under VMI as well as RMI with IS. Based on numerical experimentations, their analysis suggests that the $(z, Z)$ type of VMI agreement performs significantly better than RMI with IS in many settings, but it cannot produce savings in a few scenarios. This study also highlights that VMI can be particularly beneficial for products with high demand variance or high outsourcing cost. Archetti et al. (2007) propose a branch-and-cut algorithm considering a distribution problem in which a product has to be shipped from a supplier to several retailers under VMI system in time-varying demand setting. They find that VMI with order-up-to level policy is very rigid and it generates lesser cost savings ranging from 4.12 to $26.06 \%$ than VMI with maximum-level policy. They also compare VMI with maximum-level policy with the VMI in which shipment quantity can be any positive number and observe that further savings can be obtained if no constraint is set on the quantity to be shipped. However, in such a situation the inventory levels at the retailers may become very high and even unacceptable. Jaruphongsa, Çetinkaya, and Lee (2004) model a two-echelon VMI system under timevarying demand with time window considerations. A VMI model considering deterministic time-varying demand with an order-up-to level inventory policy is proposed by Solyali and Süral (2008). Savaşaneril and Erkip (2010) assess the 
motivation for the supplier behind joining $\mathrm{VMI}$ and $\mathrm{VMCl}$ beyond IS under service-level requirement. Their study shows that these RSP frameworks provide increased flexibility in supplier's operations and may bring additional benefits. The benefits are high under tight production capacity or under low service-level requirements. In addition, higher demand variability results in higher savings and system-wide inventory decrease; however, the inventory level at the retailer may not be lower. Furthermore, both the studies of Fry, Kapuscinski, and Olsen (2001) and Savaşaneril and Erkip (2010) show that the RSP frameworks do not bring additional benefit to IS if the conditions or terms of agreement are tight for the supplier.

Indeed, the literature on modelling of RSP initiatives is abundant using EOQ approach (see Jans and Degraeve 2008; Choi and Sethi 2010; Marquès et al. 2010; Kannan 2013 for reviews of literature). The famous EOQ modelling approach assumes a continuous time scale, constant demand and infinite time horizon. In most industrial context, however, demand is non-stationary with seasonal patterns, trends, business cycles and limited-life items. Thus, it is important to note that the case of time-varying discrete demand is particularly important in the context of RSP initiatives. Even more, today's business environment is highly dynamic and time-dependent changes in the model parameters of supply chain members can have a huge effect on the cost performance criterion of the supply chain as a whole. The literature review also confirms that RSP initiatives have not been studied sufficiently under timevarying demand environment. Therefore, this study attempts to quantify the benefits that can be realised from shift in inventory ownership and shift in decision-making power beyond IS under time-varying demand conditions. Our study is most closely related to Bookbinder, Gümüş, and Jewkes (2010) and Gümus, Jewkes, and Bookbinder (2008). However, our work is different from their work in the sense that they considered continuous demand and extended classical EOQ model to study $\mathrm{RMCl}, \mathrm{VMI}$ and $\mathrm{VMCl}$; while, we consider the case of time-varying discrete demand and extend Wagner-Whitin model. Particularly in this study, we investigate the benefits that can be accrued by a retailer, a supplier and system as a whole from RMCI and VMI beyond IS. To the best of our knowledge, RSP initiatives under time-varying demand with our perspective have not been approached in the archive literature.

\section{Problem description and mathematical models}

We consider a two-echelon serial supply chain in which a single product is delivered from a supplier to a retailer over a time horizon $T$. Each discrete time period $t=\{1, \ldots, T\}$ is of same duration. We assume that the retailer faces external deterministic time-varying demand $\mathrm{dt}$ in each time period $\mathrm{t} \mathrm{T}$. As with the end-user demand, inventory shortage is not allowed at the retailer side. Similarly, all orders of the retailer must be satisfied without backlogging. The quantity is produced or made available at most once in each period. Let Irt (Ist) be the inventory levels of the retailer (supplier) at the end of time $t$. At any period $t$, the retailer receives either nothing or a delivery xrt from the supplier. At each time period $t$, the supplier may produce quantity of size xst to replenish own stock. We consider that lead times of ordering, production and transportation are negligible and hence the required replenishment quantities are made available in the same period. Hence, any portion of xst can be shipped to the retailer to serve demand at $t$. This assumption is in line with previous studies (Fry, Kapuscinski, and Olsen 2001; Archetti et al. 2007; Solyali and Süral 2008; Savaşaneril and Erkip 2010), and also consistent with the just-in-time production concept. The space availability to store end of period inventory at both echelons is unconstrained. As it is the case in practice, it is assumed that the supplier has several sources of the product such as overtime production and/or subcontracting to meet the demand of retailer, which makes the supplier's production capacity infinite. Thus, no limits are assumed on retailer's replenishment sizes and supplier's production sizes. Inventory holding costs hst and hrt are charged for each unit of product at the end of period $t$ at the supplier and retailer locations, respectively. In addition, a fixed cost ort is incurred at every time $t$ when the retailer is replenished. As shown in Table 1 and in line with existing literature (Valentini and Zavanella 2003; Gümus, Jewkes, and Bookbinder 2008; Ben-Daya et al. 2013; Hariga and Al-Ahmari 2013), we take into account change in the cost structure of firms involved as a result of shift in decision-making responsibility and inventory ownership. A fixed setup cost Sst is incurred by the supplier if production is planned at $t$. In addition, variable production cost per unit, vst, is charged by supplier in period t. Let zst $=1(z r t=1)$ if a replenishment for the supplier (retailer) is made in period $\mathrm{t} T$ and 0 otherwise. There are fixed shipment costs ast from the supplier to the retailer. The shipment cost is charged for release as well as transportation of goods to the 
retailer. In other words, all costs linked to the transportation of items from supplier to retailer constitute shipment cost. The shipment cost may also include the costs related to receipt of the order information and the processing of it (Bookbinder, Gümüş, and Jewkes 2010). We assume that the shipment cost is incurred by the supplier in line with previous studies of Battini, Grassi, et al. (2010) and Battini, Gunasekaran, et al. (2010).

We study three types of RSP initiatives, namely, RMI, RMCl and VMI. In RMI, the retailer determines its own replenishment schedules and places orders to the supplier. Moreover, the retailer provides the supplier an access to real-time inventory levels, planned orders as well as demand forecast data. Based on this information, the supplier determines production schedule to meet retailer's orders completely. On the other hand, while inventory at the retailer's premises is owned by the supplier until it is sold or used under $\mathrm{RMCl}$, the supplier replenishes inventory at the retailer but does not own it under VMI. Under both $\mathrm{RMI}$ and $\mathrm{RMCl}$, the supplier and retailer manage their inventory independently. Under VMI, inventory is managed at both the echelons by the supplier. To assess the benefits of RMCI and VMI initiatives beyond IS we compare them to RMI on various supply chain performance measures such as cost savings, reduction in inventory levels and increase in replenishment deliveries at the retailer. Fry, Kapuscinski, and Olsen (2001) also compare VMI and RMI system with IS to isolate the benefits offered by IS and to identify those benefits that are offered by shift in decision-making power alone. To assess the motivation for the supplier behind joining VMI and VMCI beyond IS under service-level requirement, Savaşaneril and Erkip (2010) also compare VMI and VMCI policies with RMI.

Wagner and Whitin (1958) formulate a single-stage inventory lot-sizing problem considering discrete time scale, deterministic time-varying demand and finite time horizon. Previous researchers have extended the classical EOQ model to study RSP initiatives under continuous demand case. Based on the same analogy, we extend Wagner and Whitin model to a two-stage supply chain to study and compare RSP initiatives under time-varying demand.

\subsection{RMI initiative}

In RMI policy, the supplier and retailer act independently and attempt to optimise their own cost objective with available information under the given problem environment.

\subsubsection{Retailler's model under RMI}

The retailer solves a Wagner-Whitin model as defined in Equations (1)-(5) to obtain replenishment schedule that minimises its inventory carrying and ordering costs over the planning horizon.

Min $\quad \mathrm{TC}_{\text {Retailer }}^{R M I}=\sum_{t=1}^{T}\left(o_{r t} z_{r t}+h_{r t} I_{r t}\right)$

Subject to

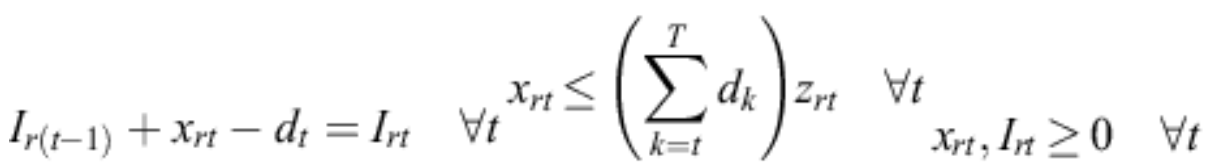

$z_{r t} \in\left\{\begin{array}{ll}0 & 1\end{array}\right\} \quad \forall t$ The objective function (1) minimises the sum of the ordering costs and the inventory carrying costs. The first term in (1) represents the order issuing costs while second term refers to the inventory holding costs over the planning horizon. It may be noted that ordering cost depends on whether the retailer is replenished or not in period $t$; therefore binary variable $z_{r t}$ is used in expression of ordering cost. The unit purchasing cost for the retailer is assumed to be stationary, thereby, not included in the objective function.

Equations (2) are the inventory balance equations at the retailer. The inventory level of the retailer at time $t$ is given by the level at time $t-1$, plus the quantities replenished at time $t$, minus end-user demands at time t. Constraints (3) 
ensure that retailer cannot place an order without charging an appropriate ordering cost. Constraints (4) and (5) are used to force non-negative values and binary restrictions in the model, respectively.

The above model gives replenishment schedule (i.e. timings and planned order quantities) for the retailer at the beginning of planning horizon. Let $\left(x_{r \tau_{1}}^{\mathrm{RMI}}, x_{r \tau_{2}}^{\mathrm{RMI}}, \ldots, x_{r \tau_{\mathrm{m}}}^{\mathrm{RMI}}\right)$ be the unique optimal solution, where $\tau_{\mathrm{j}}(j=1,2, \ldots, m)$ denotes replenishment periods. Let $\mathrm{TC}^{\mathrm{RMI}}$ be the minimum total cost of the retailer.

\subsubsection{Supplier's model under RMI}

In RMI, the supplier has the full knowledge of retailer's replenishment schedule as well as inventory positions and end-user demand over the planning horizon. Fry, Kapuscinski, and Olsen (2001) incorporate similar assumptions into the RMI system with IS to isolate the benefits offered by IS and to identify those benefits that are offered by VMI. The order quantities, given by the above retailer's model under RMI, are actually equivalent deterministic demands for the supplier originated from the retailer, which help the supplier plan production and inventory activities more efficiently than no IS. The optimal production schedule of the supplier over the planning horizon is obtained

Min $\mathrm{TC}_{\text {Supplier }}^{\mathrm{RMI}}=\sum_{t=1}^{T}\left(S_{s t} z_{s t}+v_{s t} x_{s t}+h_{s t} I_{s t}\right)$

through following Wagner-Whitin dynamic lot-sizing model.

Subject to

$$
\begin{gathered}
I_{s(t-1)}+x_{s t}-x_{r t}^{\mathrm{RMI}}=I_{s t} \quad \forall t \\
M 0008^{\prime \prime}>(8) x s t \leq \sum k=t \text { TxrtRMIzst } \forall t x s t \leq \sum k=t \text { TxrtRMIzst } \forall t x_{s t} \leq\left(\sum_{k=t}^{T} x_{r t}^{\mathrm{RMI}}\right) z_{s t} \quad \forall t \\
x_{s t}, I_{s t} \geq 0 \quad \forall t z_{s t} \in\left\{\begin{array}{ll}
0,1 & 1
\end{array} \quad \forall t\right.
\end{gathered}
$$

The objective of the model is to minimise the supplier's total cost. The first term in Equation (6) gathers the total setup costs while second term represents total variable production costs. The last term gathers total inventory holding costs for the entire planning horizon. It may be noted that setup cost depends on whether production takes place or not; therefore binary variable $\mathrm{z}_{\mathrm{st}}$ is used in expression of production setup cost. Equation (7) are the inventory balance equations of the supplier. Constraint (8) ensure that the supplier cannot produce without charging an appropriate setup cost. The other constraints of the model are self-explanatory.

Let $\left(x_{s \hat{\lambda}_{1}}^{\mathrm{RMI}}, x_{s \hat{\lambda}_{2}}^{\mathrm{RMI}}, \ldots, x_{s \hat{\lambda}_{n}}^{\mathrm{RMI}}\right)$ be the unique optimal solution and ${ }^{\mathrm{TC}_{\text {Supplier }}^{\mathrm{RMI}}}$ be the minimum total production and inventory costs of the supplier. Here, $\lambda \mathrm{i}(i=1,2, \ldots, n)$ denotes production periods. In addition, the supplier is charged fixed shipment cost $\mathrm{a}_{\mathrm{st}}$ every time the retailer is replenished. Now, optimal total system cost under RMI initiative can be expressed by Equation (11). The last term gathers total shipment costs, where $m(m \leq T)$ is total number of

$$
\mathrm{TC}_{\text {System }}^{\mathrm{RMI}^{*}}=\mathrm{TC}_{\text {Retailer }}^{\mathrm{RMI}^{*}}+\mathrm{TC}_{\text {Supplier }}^{\mathrm{RMI}^{*}}+\sum_{t=1}^{m} a_{s t}
$$

shipments planned at the retailer.

\subsection{RMCI initiative}

Shift in inventory ownership is a popular relationship where supplier retains ownership of the inventory and gets paid from the retailer based on actual units sold. For each item sold, the retailer will deduct an agreed percentage 
from the selling price and remits the balance to the supplier. Here, the supplier bears opportunity cost of the retailer's on-site stock and the retailer decides the timings and order quantities. Thereby, it is called $\mathrm{RMCl}$.

The inventory carrying cost at the retailer, $h_{r t}$ is calculated as the sum of two principal components: the financial component, $h_{r t}^{f}$, and the stock component, $h_{r t}^{s}$. The $h_{r t}^{f}$ refers to the opportunity costs of a firm when it invests financial resources in the production of a product. The $h_{r t}^{s}$ refers to the warehousing costs of the product such as stocking, handling, insurance, obsolescence, shrinkage, etc. Under RMI, the retailer bears total inventory carrying cost, i.e. hrt. However, under RMCl, the supplier is responsible for providing the capital and paying taxes. Similar inventory holding cost structures have been used by Braglia and Zavanella (2003), Persona, Grassi, and Catena (2005) and Gümüs, Jewkes, and Bookbinder (2008) in modelling CS policies.

The following model is used to optimise replenishment schedule of the retailer under RMCl partnership.

Min $\mathrm{TC}_{\text {Retailer }}^{\mathrm{RMCI}}=\sum_{t=1}^{T}\left(o_{r t} z_{r t}+h_{r t}^{s} I_{r t}\right)$

Retailer's model:

Subject to constraints (2)-(5).

Let $\left(x_{r \tau_{1}}^{\mathrm{RMCI}}, x_{r \tau_{2}}^{\mathrm{RMCI}}, \ldots, x_{r \tau_{m^{\prime}}}^{\mathrm{RMCI}}\right)$ be the unique optimal solution and $\mathrm{TC}_{\mathrm{Retailer}}^{\mathrm{RMCI}}$ be the minimum total costs of the retailer. For given order issuing cost, comparison of the retailer's models under $\mathrm{RMI}$ and $\mathrm{RMCl}$ suggests that the shift in inventory ownership induces the retailer to order larger quantities, i.e. $m^{\prime} \leq m$.

The supplier then uses the revised replenishment schedule of the retailer in the model defined in Equations (6)(10). Let $\left(x_{s \hat{\lambda}_{1}}^{\mathrm{RMCI}}, x_{s \hat{\lambda}_{2}}^{\mathrm{RMCI}}, \ldots, x_{s \lambda_{n^{\prime}}}^{\mathrm{RMCI}}\right)$ be the unique optimal solution and $\mathrm{TC}_{\text {Supplier be the minimum total }}^{\mathrm{RMCI^{* }}}$ production and inventory costs of the supplier. In addition, the supplier is charged fixed shipment cost $a_{\text {st }}$ every time the retailer is replenished as well as opportunity $\operatorname{cost} h_{r t}^{f}$ for the remaining inventory in each period at the retailer. Now, optimal total system cost under $\mathrm{RMCl}$ initiative can be expressed by Equation (13). The last term gathers total opportunity

$\mathrm{TC}_{\text {System }}^{\mathrm{RMCI}^{*}}=\mathrm{TC}_{\text {Retailer }}^{\mathrm{RMCI}^{*}}+\mathrm{TC}_{\text {Supplier }}^{\mathrm{RMCI}^{*}}+\sum_{t=1}^{m^{\prime}} a_{s t}+\sum_{t=1}^{T} h_{r t}^{f} I_{r t}$

costs at the retailer.

One can observe from Equations (11) and (13) that independent decision-making does not allow optimisation of shipment cost of the supplier under both the $\mathrm{RMI}$ and $\mathrm{RMCl}$. In addition, under $\mathrm{RMCl}$, the costs borne by the supplier in owning inventory at the retailer is also untapped.

\subsection{VMI initiative}

A fixed cost $o_{r t}$ is incurred at every time that the retailer places an order under $\mathrm{RMI}$ or $\mathrm{RMCl}$. On the other hand, VMI leads to transfer of order issuing cost, $o_{r t}$, from the retailer to the supplier as a result of shift in decision-making power. Moreover, we assume that the supplier incurs $(1-\beta) o_{r t}$ for issuing order at $t$ on behalf of the retailer under $\mathrm{VMI}$, where $\beta$ is order issuing efficiency factor of the supplier. In practice, the supplier should be more efficient $(0 \leq \beta<1)$ than the retailer in issuing orders as he/she is placing orders from his/her own organisation (see Bookbinder, Gümüş, and Jewkes 2010).

With this background, a mathematical formulation under VMI partnership may be stated as follows: 
$\operatorname{Min} \mathrm{TC}_{\mathrm{System}}^{\mathrm{VMI}}=\sum_{t=1}^{T}\left\{S_{s t} z_{s t}+(1-\beta) o_{r t}+v_{s t} x_{s t}+h_{s t} I_{s t}+a_{s t} z_{r t}\right\}+\sum_{t=1}^{T} h_{r t} I_{r t}$

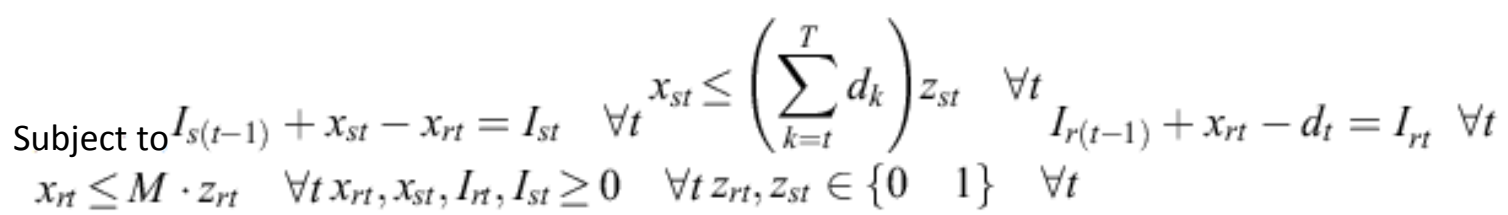

$$
x_{n t} \leq M \cdot z_{r t} \quad \forall t x_{r t}, x_{s t}, I_{n t}, I_{s t} \geq 0 \quad \forall t z_{r t}, z_{s t} \in\left\{\begin{array}{ll}
0 & 1
\end{array}\right\} \quad \forall t
$$

The objective function minimises the total system-wide costs. While first five terms in Equation (14) gather total costs of the supplier, last term represents total inventory carrying costs of the retailer under VMI. One can observe that shift in decision-making power enables optimisation of shipment costs, $a_{s t} z_{r t}$, over the finite planning horizon. Equations (15) are the inventory balance equations of the supplier. Constraints (16) ensure that supplier cannot produce without charging an appropriate production setup cost. Equations (17) are the inventory balance equations of the retailer. Constraints (18) ensure that shipment and ordering costs are charged whenever the retailer is replenished, where $M$ is a very large number. Constraints (19) and (20) are used to force non-negative values and binary restrictions in the model, respectively.

Now, we discuss a set of important properties of optimal solutions for the above models under the assumptions considered in this research. These properties are useful in solving large scale problems.

Property 1. The optimal solutions at both the echelon satisfy the well-known Wagner-Whitin zero-inventory ordering characteristic. The optimal replenishment policy at the retailer is such that $I_{r(t-1)} x_{r t}=0$ for all $t=1, \ldots, T$, i.e. if a replenishment is planned at period $t\left(x_{r t}>0\right)$ then $I_{r(t-1)}=0$. Similarly, the optimal production policy at the supplier is such that $I_{s(t-1)} \cdot x_{s t}=0$ for all $t=1, \ldots, T$, i.e. if a production is planned at period $t\left(x_{s t}>0\right)$ then $I_{s(t-1)}=0$.

Property 2. If per unit variable production cost remains stationary then a production is planned only when a replenishment is made (i.e. for a given $t, x_{s t}>0$ only if $x_{r t}>0$ and $v_{s t}$ is stationary). However, this property may not hold if per unit variable production cost is non-stationary. We can plan a production in advance by k periods to save on production cost, where $\mathrm{k}=\mathrm{t}-1, \mathrm{t}-2, \ldots, \mathrm{t}-\mathrm{i}+1$ and $\mathrm{i}$ is preceding production period, (i.e. for a given $\mathrm{t}, \mathrm{x}_{\mathrm{s}(\mathrm{t}-\mathrm{k})}>0$ only if $\mathrm{x}_{\mathrm{rt}}>0$ and $\left.\left(v_{s t}-v_{s(t-k)}\right)>\sum_{u=k}^{t} h_{s u}\right)$.

Property 3. The production cycles can be at most equal to replenishment cycles (i.e. $n \leq m$ ). Thus, under the optimal policy, each time either the retailer is to be replenished solely by a single production or the produced quantity may serve several consecutive replenishments.

\section{Numerical experiments}

In this section, we conduct numerical experiments to explore the value of shift in inventory ownership as well as shift in decision-making power beyond IS, the allocation of benefits across supply chain partners and the impact of system parameters on supply chain performance measures such as reduction in costs and inventory levels as well as increase in replenishment frequencies at the retailer.

\subsection{Experimental design}

To insure that the results are reflective of general type of business environment, and not a specific scenario, we use a test set involving a variety of demand and cost parameters. We conduct a full factorial analysis by using the following sets of parameters: demand patterns DP $\in\{$ STAT, RAND, SIN1, SIN2, LCY1, LCY2\}, supplier's per unit variable production cost $\mathrm{v}_{\mathrm{st}} \in\{$ STAT, RAND1, RAND2 $\}$, supplier's setup cost $\mathrm{s}_{\mathrm{st}} \in\{10,500,2500\}$, supplier's shipment cost $\mathrm{a}_{\mathrm{st}} \in\{0,500,1500\}$, order issuing cost $\mathrm{o}_{\mathrm{rt}} \in\{50,400,1200\}$ and supplier's order issuing efficiency factor $\beta \in\{0$, $0.4\}$. In all experiments, we set $h_{s t}=1, h_{r t}=2$ and $h_{r t}^{f}=40 \%$ of $h_{r t}$. The planning horizon is set to 24 periods with no initial inventory in all the experiments. While per unit variable production cost used in numerical study can vary over 
time, the remaining parameters are assumed stationary over time. Since, in practice, variable production cost is more likely to change with respect to time than other cost parameters because of varying levels of regular production capacity availability. If this is the case, supplier incurs higher per unit variable production cost due to overtime production or subcontracting to meet retailer's orders completely. Even more, we consider stationary values of setup, shipment and order issuing costs to investigate how supply chain performance measures are affected by varying levels of these cost parameters.

Figure 2 illustrates the demand patterns under consideration. Demand patterns used reflect common time-varying demand structures. Stationary demand over time is reflected by STAT pattern, whereas erratic or random demand is reflected by RAND pattern. Thus, the STAT and the RAND patterns represent the extreme cases of stationary/dynamic dichotomy. The sinusoidal patterns SIN1 and SIN2 as well as the life cycle patterns LCY1 and LCY2 are generated with different definitions to capture the different levels of variability of the same underlying demand patterns. Furthermore, to abandon any effect that may occur due to variation in the total demand, these demand patterns are designed in such a way that the total demand over the planning horizon is the same for all the demand patterns. The total mean demand summed over the planning horizon for each demand pattern is 2400 units. In other words, for all the demand patterns the average of mean demands over the planning horizon is fixed at 100 units.

Figure 2. End-user demand patterns for 24-periods.

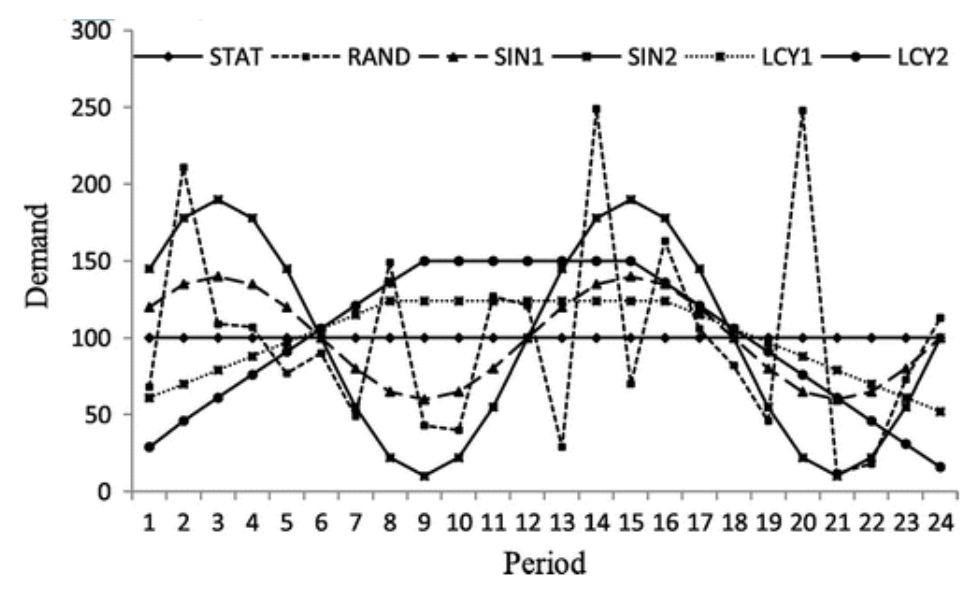

Figure 3 illustrates per unit variable production cost structures under consideration. The STAT pattern reflects the case where per unit variable production cost is stationary over time. The random cost structures RAND1 and RAND2 are generated by imitating uniform distribution with different minimum and maximum values. Thus, the timedependent changes in per unit variable production cost increases as we move from STAT structure to RAND2 structure. We remark that for all cost patterns the average of mean per unit variable production costs over the planning horizon is fixed at 10 monetary units.

Figure 3. Per-unit variable production cost structures for 24-periods.

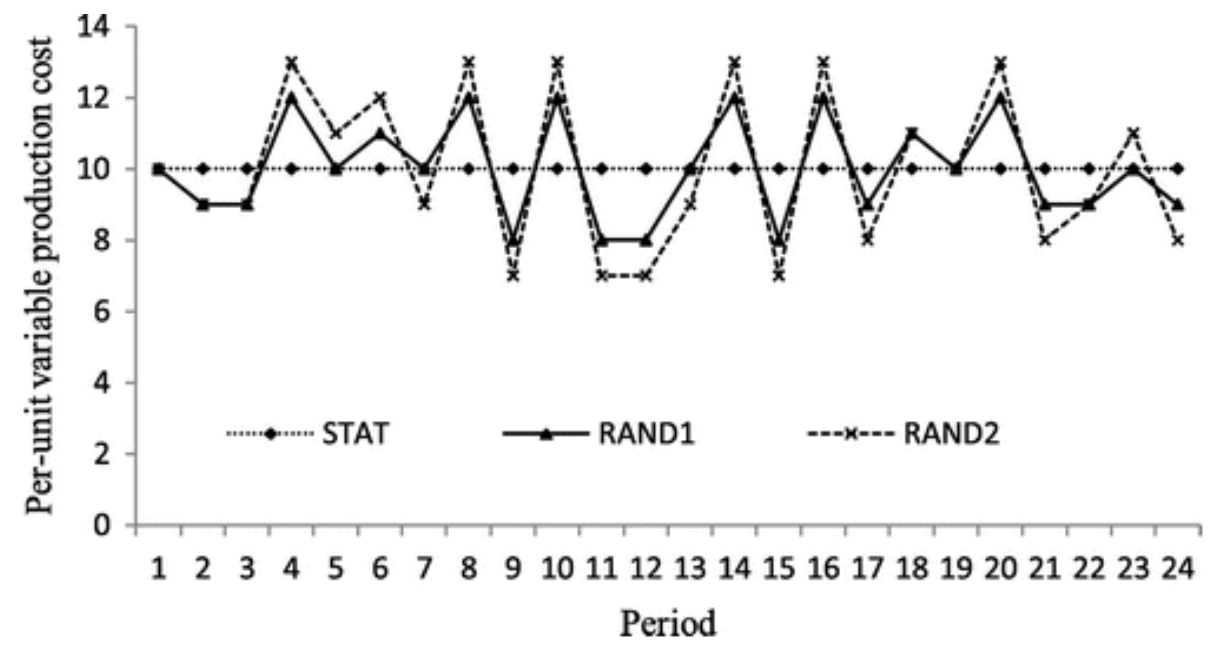




\subsection{Comparison of RMI and RMCI}

We solve and compare 486 test instances for both the RMI and RMCl initiatives by varying DP, vst, Sst, ast and ort. The results of experimental study reveal that average on-site inventory level at the retailer increases from 1333 units under RMI to 1957 units under RMCl over the planning horizon due to decrease in shipment frequencies. However, the retailer always incurs lesser costs under $\mathrm{RMCl}$ compared to $\mathrm{RMI}$ because of significant reduction in total order issuing costs and transfer of opportunity costs to the supplier. The retailer's cost savings vary from 0 to $20.03 \%$ and depend on demand pattern and order issuing cost. The average cost saving of the retailer across problem sets is $12.46 \%$. Figure 4 exhibits the average percentage cost savings of the retailer with respect to order issuing cost. We observe that cost savings of the retailer increase as order issuing cost changes from low level to high level. Moreover, Figure 5 illustrates the effects of demand patterns on the retailer's cost savings. The experiments indicate that, as the variability of the same demand pattern increases, the cost savings of the retailer increase.

Figure 4. Impact of order issuing cost on the retailer's cost savings.

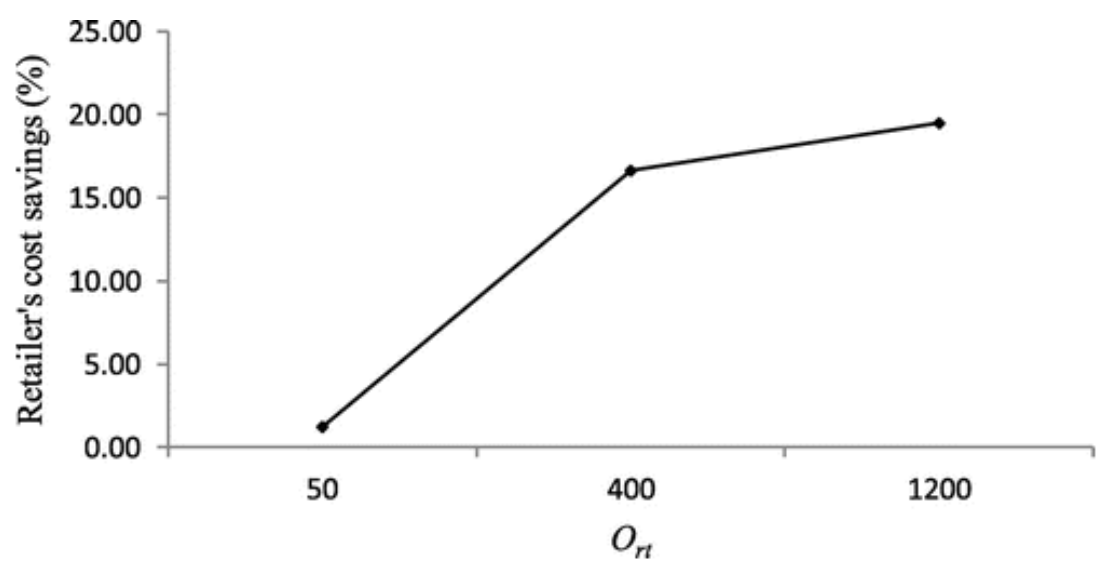

Figure 5. Impact of demand pattern on the retailer's cost savings.

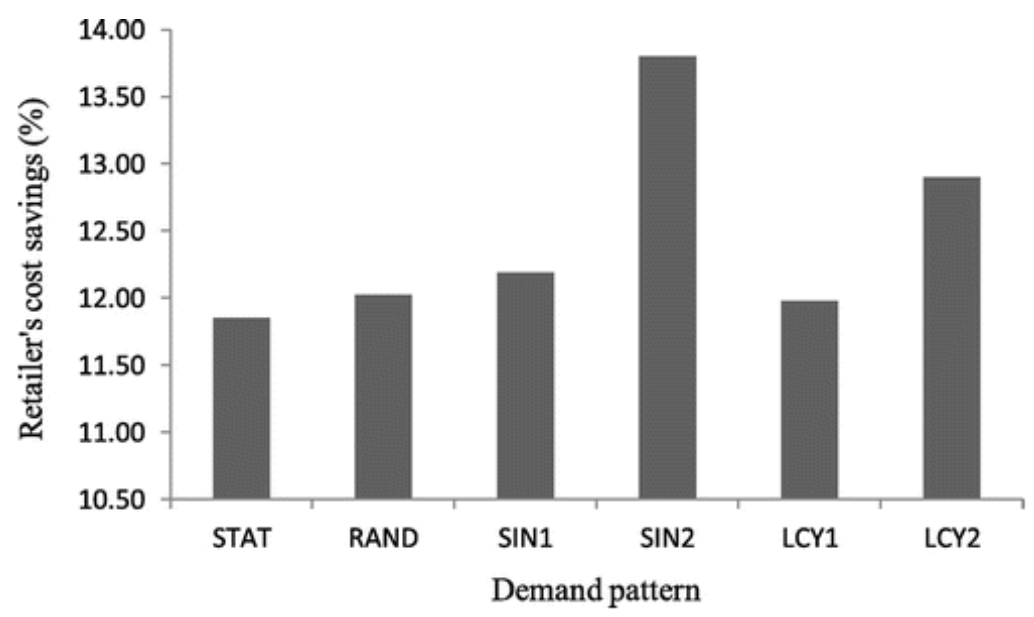

The findings based on the results of the numerical experiments reveal that the shift in inventory ownership beyond IS may or may not decrease cost and inventory of the supplier. The system parameters such as DP, vst, Sst, ast and ort affect the cost savings of the supplier. Across all the test instances, it is seen that the supplier's cost savings can be as high as $10.43 \%$ (when setup and shipment costs are high, order issuing cost is low, demand pattern is RAND and variable production cost is STAT) and as low as $-24.19 \%$ (when setup and shipment costs are low, order issuing cost is high, demand pattern is LCY2 and variable production cost is RAND2). The shift in inventory ownership reduces inventory of the supplier by $7.31 \%$ and increases cost by $2.49 \%$ on average. We observe that the losses of the supplier under $\mathrm{RMCl}$ decrease when setup and shipment costs change from low level to high level as well as variability of the same demand pattern increases. 
The system-wide cost saving across the test instances varies from -7.20 to $11.11 \%$. The shift in inventory ownership reduces cost incurred by system as a whole by $1.33 \%$ and increases system inventory by $8.25 \%$ on average. Figures 6-9 exhibit the impacts of system parameters on system-wide cost savings under RMCl. We observe from Figure 6 that system-wide cost saving is realised under $\mathrm{RMCl}$, as compared to $\mathrm{RMI}$, when shipment cost $\left(\mathrm{a}_{\mathrm{st}}\right)$ is 500 monetary units and more. One can also note that the cost savings generally increase under $\mathrm{RMCl}$ as setup cost changes from low level to high level. Figure 7 illustrates that cost savings are significantly higher for static demand pattern than sinusoidal and life cycle demand patterns. Additionally, system-wide cost savings increase as the variability of the same demand pattern increases. For problem setting considered in this paper, we observe from Figure 8 that the increase in the variability of per unit production cost leads to decrease in system-wide cost saving.

Figure 6. Impact of setup and shipment cost on the system-wide cost savings.

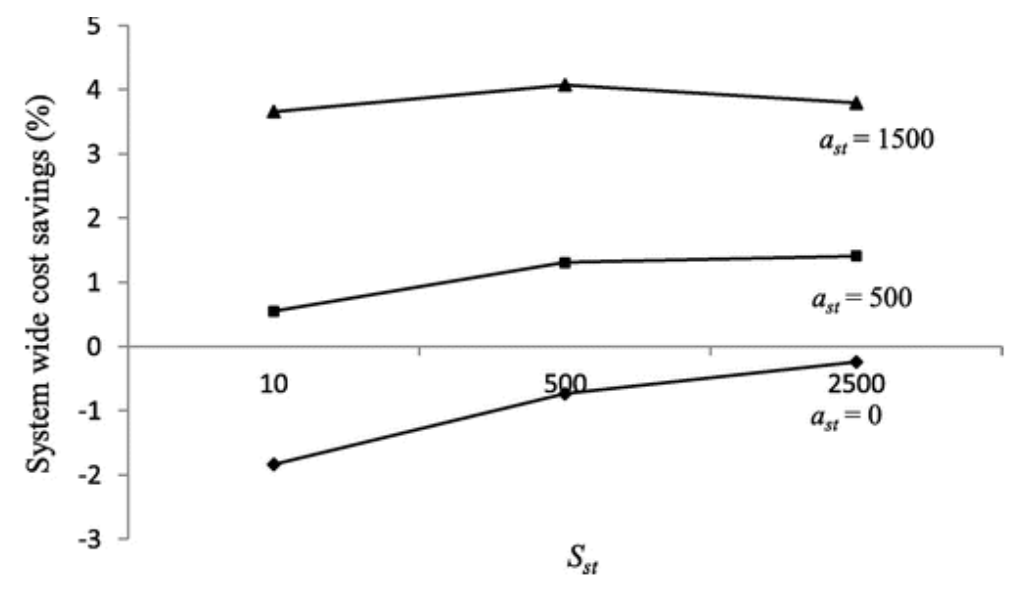

Figure 7. Impact of demand pattern on system-wide cost savings.

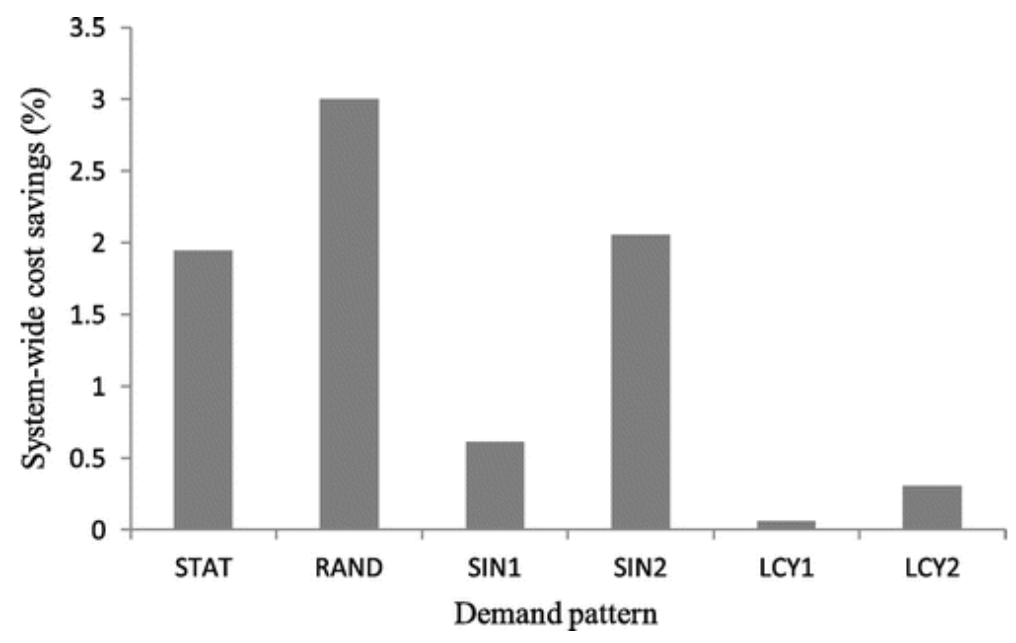

Figure 8. Impact of variable production cost structures on system-wide cost savings.

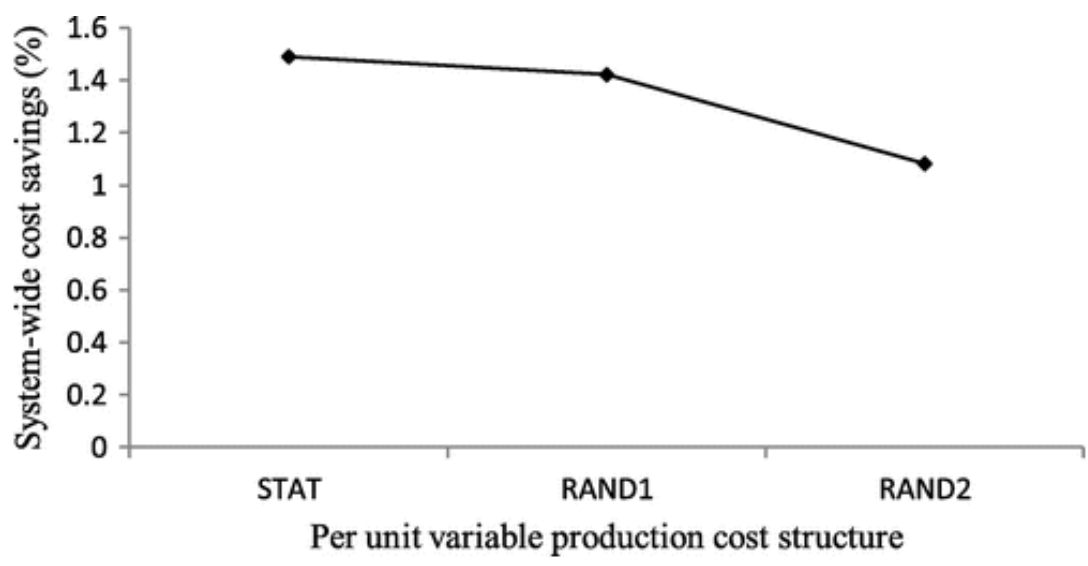


The magnitude of order issuing cost significantly affects the system-wide cost savings achieved from RMCl compared to RMI. We observe from Figure 9 that the RMCI performs significantly better for intermediate values of order issuing cost. For given inventory holding cost (say hrt $=2$ ), system cost savings increase from 0.91 to $2.34 \%$ on average as ort increases from 50 to 400 . Whereas, when ort $=1200$, the average cost saving is $0.74 \%$. These results can be explained by looking at the retailer's replenishment behaviour under $\mathrm{RMI}$ and $\mathrm{RMCl}$. When order issuing cost is zero (say very low) or inventory holding cost is significantly high, the inventory is replenished in every period at the retailer under both $\mathrm{RMI}$ and $\mathrm{RMCl}$ strategies irrespective of magnitude of opportunity cost of carrying inventory. Under such a situation, $\mathrm{RMCl}$ is not attractive for the supplier and system as a whole as replenishment frequencies do not decrease. Now, when order issuing cost is extremely large or inventory holding cost is very low, the inventory at the retailer is not replenished frequently under RMI; thereby, shift in inventory ownership would not be a viable option for supplier and system as a whole. Therefore, we observe in line with Choudhary and Shankar (2011) that the replenishment decisions and subsequently cost saving accrued by moving from RMI to RMCl depend on demand structure and trade-off between holding cost and order issuing cost.

Figure 9. Impact of order issuing cost on the system-wide cost savings.

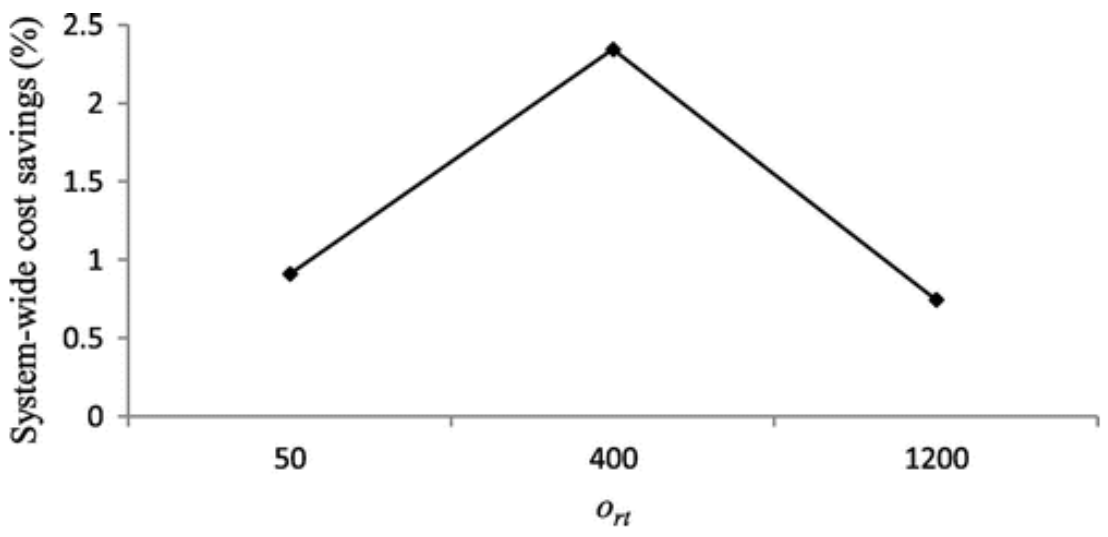

Under RMCl, as compared to RMI, our experimental results reveal that cost savings for the supplier can be achieved if the supplier prefers fewer shipments due to high setup and shipment costs and the shift in inventory ownership induces the retailer to order larger quantities. In both $\mathrm{RMI}$ and $\mathrm{RMCl}$, the supplier and retailer act independently. The retailer decides the timings and order quantities according to its need and the quantity ordered can be different from one time period to another particularly when demand is dynamic. The supplier then responds to meet the retailer's orders. Obviously, the retailer would be always better-off under RMCl compared to a situation when supplier does not consign the stock for the optimal replenishment schedule decided by the retailer under RMI due to transfer of the opportunity cost of carrying inventory. However, how would RMCl benefit the supplier and system as a whole can be explained by observing a problem setting in which the retailer's optimal replenishment schedule may not lead to optimal production schedule for the supplier particularly when retailer places smaller orders too frequently by striking a trade-off between ordering and inventory holding costs; and the supplier prefers a fewer production setups and replenishment deliveries because of high setup and shipment costs, respectively. In such a situation, the supplier would doubtlessly prefer that the retailer increases the sizes of orders particularly when large capacity is available with the supplier all the time. Now, for given ordering cost, larger orders may be lucrative to the retailer when inventory holding cost decreases, which is only possible under same business environment if the supplier bears the opportunity cost. The replenishment schedule decided under RMI may not remain optimal for the retailer due to shift in trade-off point as a result of decrease in inventory carrying cost with a transfer of opportunity cost. Thereby, shift in inventory ownership influences the retailer's replenishment policy to make it beneficial for the supplier and system as a whole under specific business settings.

We observe that the supplier gains by moving from RMI to RMCl when saving obtained due to reduction in inventory and setup costs is higher than additional cost burden of owning the inventory at the retailer and increase (if any) in variable production cost. However, $\mathrm{RMCl}$ may not produce benefits to the supplier when supplier's capacity and setup cost are low or/and the retailer does not place orders too frequently under RMI. Obviously, as compared to 
$\mathrm{RMI}$, reduction in system-wide cost can be realised under $\mathrm{RMCl}$ when either the partners gain or decrease in cost incurred by the retailer is higher than increase in cost incurred by the supplier.

\subsection{Comparison of RMI and VMI}

We solve and compare 972 test instances for both the RMI and VMI initiatives by varying DP, vst, Sst, ast, ort and $\beta$. Our aim is to figure out the magnitude of benefits which can be accrued by shift in decision-making power beyond and above IS under different business settings. Table 2 presents the impacts of changes in system parameters on the supply chain performance measures. Below, we summarise our findings from the results of the numerical experiments.

Table 2. Experimental results summary: RMI vs VMI.

\begin{tabular}{|c|c|c|c|c|c|c|}
\hline \multirow[t]{3}{*}{ Independent system parameters } & \multicolumn{6}{|c|}{ Dependent supply chain performance measures } \\
\hline & \multicolumn{2}{|c|}{ Ave. cost savings $(\%)$} & \multicolumn{2}{|c|}{ Ave. inventory reduction $(\%)$} & \multicolumn{2}{|c|}{ Ave. increase in rep. freq. (\%) } \\
\hline & $\boldsymbol{\beta}=\mathbf{0}$ & $\beta=0.4$ & $\boldsymbol{\beta}=\mathbf{0}$ & $\beta=0.4$ & $\boldsymbol{\beta}=\mathbf{0}$ & $\beta=0.4$ \\
\hline \multicolumn{7}{|l|}{ Demand pattern (DP) } \\
\hline STAT & 9.86 & 13.04 & -24.95 & -23.38 & -39.59 & -31.58 \\
\hline RAND & 8.92 & 12.10 & -22.08 & -17.17 & -39.41 & -30.95 \\
\hline SIN1 & 10.99 & 14.23 & -10.41 & -4.07 & -37.17 & -28.20 \\
\hline SIN2 & 9.21 & 12.12 & -11.25 & -6.35 & -38.52 & -31.58 \\
\hline LCY1 & 10.59 & 13.81 & -8.85 & -3.91 & -37.20 & -30.00 \\
\hline LCY2 & 9.85 & 13.01 & -20.25 & -15.43 & -39.77 & -31.66 \\
\hline \multicolumn{7}{|l|}{ Variable production cost $\left(v_{s t}\right)$} \\
\hline STAT & 8.45 & 11.45 & -34.00 & -26.65 & -39.27 & -31.05 \\
\hline RAND1 & 10.61 & 13.82 & -11.20 & -7.47 & -37.72 & -29.74 \\
\hline RAND2 & 10.65 & 13.89 & -3.69 & -1.03 & -38.84 & -31.21 \\
\hline \multicolumn{7}{|l|}{ Setup cost $\left(s_{s t}\right)$} \\
\hline 10 & 9.45 & 13.50 & -32.68 & -22.93 & -29.79 & -22.33 \\
\hline 500 & 10.42 & 13.57 & -16.53 & -12.04 & -39.63 & -31.78 \\
\hline 2500 & 9.83 & 12.09 & 0.32 & -0.19 & -46.42 & -37.88 \\
\hline \multicolumn{7}{|l|}{ Order issuing cost $\left(o_{r t}\right)$} \\
\hline 50 & 16.54 & 17.25 & -20.76 & -19.86 & -49.01 & -47.55 \\
\hline 400 & 7.62 & 10.62 & -19.64 & -16.83 & -38.47 & -28.36 \\
\hline 1200 & 5.55 & 11.29 & -8.51 & 1.54 & -28.35 & -16.08 \\
\hline \multicolumn{7}{|l|}{ Shipment cost $\left(a_{s t}\right)$} \\
\hline 0 & 1.61 & 6.25 & 5.29 & 9.28 & -12.12 & 3.24 \\
\hline 500 & 7.96 & 10.92 & -10.63 & -6.06 & -44.71 & -38.86 \\
\hline 1500 & 20.14 & 21.99 & -43.55 & -38.37 & -59.01 & -56.37 \\
\hline All instances & 9.90 & 13.05 & -16.30 & -11.72 & -38.61 & -30.66 \\
\hline
\end{tabular}

\subsubsection{Impact of demand patterns on performance measures}

Under VMI, as compared to RMI, it is apparent from Table 2 that system-wide cost savings increase on the average when demand pattern changes from a static to life cycle to sinusoidal structures. Even more, when variable production cost is non-stationary, we observe that system-wide cost savings reduce as the variability of the same underlying demand pattern increases. For example, changing demand pattern SIN1-SIN2, system cost saving reduces from 10.99 to $9.21 \%$.

\subsubsection{Impact of variable production cost on performance measures}

We observe from Table 2 that per unit variable production cost structures have significant impacts on both the system-wide percentage cost saving and inventory reduction performance measures. Examination of results reveals that increase in the variability of the variable production cost has positive impacts on system-wide cost saving and inventory reduction. Under $\mathrm{VMI}$, as compared to RMI, it is seen that total costs incurred by system as a whole decrease as the variability of the variable production cost increases. For example, moving from STAT to RAND2 variable production cost structure results into increase in cost savings from 8.45 to $10.61 \%$. Similarly, inventory 
levels change from -34 to $-3.69 \%$ as production cost structure varies from STAT to RAND2. Thus, switching from RMI to VMI is more attractive when time-dependent variation in variable production cost is large.

\subsubsection{Impact of setup cost on performance measures}

The impact of supplier's setup cost on the system-wide inventory reductions and increase in replenishment frequency at the retailer is significant. This observation can also be verified from Table 2. As compared to RMI, it is seen that replenishment frequencies decrease under VMI when setup cost of the supplier changes from low level to high level. Since, any increase or decrease in setup cost does not influence ordering decision of the retailer under RMI. Under RMI, on-site stock of the supplier increases significantly when the retailer places frequent orders and setup cost changes from low level to high level. On the other hand, under VMI, replenishment frequencies at the retailer decrease with increasing setup cost. The inventory at the retailer is significantly higher under VMI than RMI because shipment sizes from supplier to retailer increase. The system-wide inventory, however, may be lower under VMI than RMI when decrease in supplier's inventory levels is higher than increase in inventory levels at the retailer. Thus, for given order issuing cost, the cost savings of the supplier increase and retailer's savings decrease as setup cost changes from low level to high level. This also explains why the impact of variation in supplier's setup cost on system-wide cost savings is trivial.

\subsubsection{Impact of order issuing cost on performance measures}

It is evident from Table 2 that the order issuing cost has significant impacts on the three supply chain performance measures. Under VMI, the supplier would replenish the retailer less frequently than RMI to save on ordering, shipment and setup costs. It is observed that replenishment frequency decreases with increase in order issuing cost under both RMI and VMI. However, the gap between the replenishment frequencies of RMI and VMI decreases as order issuing cost increases. For example, when demand as well as variable production cost are STAT and ast $=$ Sst $=500$, the replenishment frequency reduces from 24 to 7 under RMI, whereas it decreases from 12 to 6 under VMI as order issuing cost changes from 50 to 1200. Thereby, increase in inventory levels at the retailer reduces substantially under VMI as order issuing cost increases. This explains why increase in system-wide inventory is lower when order issuing cost takes higher values.

\subsubsection{Impact of shipment cost on performance measures}

Table 2 illustrates that decrease in replenishment frequencies with increasing shipment cost lead to increase in inventory level at the retailer under VMI as compared to RMI. As a result, system-wide inventory increases as shipment cost changes from low level to high level. However, the system-wide cost incurred under VMI decreases because savings obtained from reduction in total shipment and order issuing costs are higher than increase in total inventory holding costs. Here, for the given shipment cost, we can also logically conclude that cost savings would decrease with increase in per unit inventory holding cost. This result underlines that VMI is more attractive than RMI for the supplier and system as whole when shipment cost is large. On the contrary, the retailer may become worseoff if cost incurred to carry increased stock is greater than transfer of order issuing costs to the supplier due to shift in decision-making power. For example when shipment cost changes from 0 to 500 , cost savings of the supplier increases from $-10.77 \%$ to $6.14 \%$, whereas retailer's savings deteriorate from 60.98 to $-79.71 \%$. In such a situation, VMI can be attractive to the retailer only when the supplier either provides price discounts or consigns the stock.

\subsubsection{Impact of order issuing efficiency factor on performance measures}

The magnitude of order issuing efficiency factor $(\beta)$ has positive impacts on the three supply chain performance measures considered in this study. As expected, examination of Table 2 reveals that system-wide cost savings and replenishment frequencies increase when $\beta$ changes from low level to high level. Under VMI, it is observed increase in $\beta$ leads to decrease in shipment sizes or more frequent deliveries at the retailer. We observe that inventory level at the retailer is significantly higher under VMI than RMI when $\beta=0$. The increase in retailer's on-site stock decreases as $\beta$ changes from 0 to 0.4 . For given setup and shipment costs, cost savings are greater with increase in $\beta$ when order issuing cost is large. 
The shift in decision-making power results in decrease in replenishment frequency at the retailer in majority of the settings. Consequently, system-wide inventory increases when we switch from RMI to VMI. For instance, inventory level at the retailer goes up by 1885 units on average, whereas on-site stock of the supplier reduces by 1690 units. Thereby, average system inventory increases by 195 units over the planning horizon. However, the results of full factorial experiment reveal that VMI can produce system-wide cost savings ranging from 0.08 to $37.01 \%$ as compared to RMI even if $\beta$ is zero. The shift in decision-making power produce cost savings through consolidation of production, ordering and replenishment quantities. The cost savings can also be achieved from reduction in order issuing cost if the supplier is efficient in doing so under VMI. These observations can be verified referring Table 3.

Table 3. Impact of interaction among shipment, ordering and setup costs on performance measures.

\begin{tabular}{|c|c|c|c|c|c|c|c|c|}
\hline \multirow{2}{*}{\multicolumn{3}{|c|}{ Independent system parameters }} & \multicolumn{6}{|c|}{ Dependent supply chain performance measures } \\
\hline & & & \multicolumn{2}{|c|}{ Ave. cost savings $(\%)$} & \multicolumn{2}{|c|}{ Ave. inventory reduction $(\%)$} & \multicolumn{2}{|c|}{ Ave. increase in rep. freq. (\%) } \\
\hline$a_{s t}$ & $o_{r t}$ & $s_{s t}$ & $\boldsymbol{\beta}=\mathbf{0}$ & $\beta=0.4$ & $\boldsymbol{\beta}=\mathbf{0}$ & $\beta=0.4$ & $\boldsymbol{\beta}=\mathbf{0}$ & $\beta=0.4$ \\
\hline \multirow[t]{9}{*}{0} & \multirow[t]{3}{*}{50} & 10 & 0.08 & 2.00 & 0.98 & 0.91 & -2.46 & -0.52 \\
\hline & & 500 & 0.08 & 1.65 & 0.70 & 0.70 & -5.38 & -1.72 \\
\hline & & 2500 & 0.04 & 1.23 & 0.01 & 0.01 & -6.35 & -0.72 \\
\hline & \multirow[t]{3}{*}{400} & 10 & 1.78 & 8.22 & 16.34 & 33.45 & -5.08 & 19.92 \\
\hline & & 500 & 1.78 & 6.15 & 6.98 & 0.17 & -23.58 & -1.08 \\
\hline & & 2500 & 1.58 & 5.07 & 0.80 & -1.42 & -24.59 & -0.51 \\
\hline & \multirow[t]{3}{*}{1200} & 10 & 2.90 & 12.79 & 14.27 & 36.04 & -5.82 & 19.71 \\
\hline & & 500 & 3.16 & 10.61 & 4.18 & 16.76 & -14.68 & 2.25 \\
\hline & & 2500 & 3.05 & 8.53 & -2.83 & -3.00 & -25.93 & -8.20 \\
\hline \multirow[t]{9}{*}{500} & \multirow[t]{3}{*}{50} & 10 & 13.92 & 14.46 & -39.98 & -26.38 & -59.54 & -58.83 \\
\hline & & 500 & 15.15 & 15.55 & -1.35 & -2.78 & -66.64 & -66.64 \\
\hline & & 2500 & 12.64 & 12.94 & -0.38 & 1.21 & -69.20 & -68.03 \\
\hline & \multirow[t]{3}{*}{400} & 10 & 4.61 & 8.05 & -28.54 & -23.16 & -28.69 & -26.62 \\
\hline & & 500 & 6.23 & 9.03 & -12.37 & -9.17 & -44.39 & -38.46 \\
\hline & & 2500 & 5.81 & 7.75 & -1.42 & -1.84 & -49.41 & -43.97 \\
\hline & \multirow[t]{3}{*}{1200} & 10 & 3.56 & 10.81 & -3.22 & 11.56 & -16.27 & -5.82 \\
\hline & & 500 & 4.62 & 10.50 & -15.38 & 3.61 & -28.31 & -15.48 \\
\hline & & 2500 & 5.08 & 9.22 & 2.00 & -2.83 & -39.95 & -25.93 \\
\hline \multirow[t]{9}{*}{1500} & \multirow[t]{3}{*}{50} & 10 & 36.32 & 36.53 & -103.32 & -103.63 & -73.36 & -73.36 \\
\hline & & 500 & 37.01 & 37.18 & -42.54 & -42.88 & -77.39 & -77.39 \\
\hline & & 2500 & 33.59 & 33.71 & 4.68 & 4.68 & -80.74 & -80.74 \\
\hline & \multirow[t]{3}{*}{400} & 10 & 14.31 & 16.24 & -113.31 & -102.09 & -49.96 & -47.98 \\
\hline & & 500 & 16.59 & 18.11 & -53.84 & -50.33 & -56.59 & -54.97 \\
\hline & & 2500 & 15.93 & 16.96 & 2.92 & 2.91 & -67.22 & -61.62 \\
\hline & \multirow[t]{3}{*}{1200} & 10 & 7.58 & 12.42 & -31.63 & -22.41 & -31.75 & -27.51 \\
\hline & & 500 & 9.20 & 13.33 & -41.03 & -24.43 & -39.68 & -32.54 \\
\hline & & 2500 & 10.76 & 13.38 & -2.94 & -1.41 & -54.37 & -51.19 \\
\hline \multicolumn{3}{|c|}{ All instances } & 9.90 & 13.05 & -16.30 & -11.72 & -38.61 & -30.66 \\
\hline
\end{tabular}

We observe that when the retailer does not place frequent orders under RMI and/or where shipment cost is negligible; the benefits of switching from RMI to VMI are at its lowest value. The results summarised in Table 3 indicate that moving from RMI to VMI is more attractive when shipment cost is at high level and order issuing cost is at low level. This is because of the fact that such a situation provides maximum opportunity for aggregating ordering and shipment quantities. We also observe that savings obtained through shift in decision-making power are not equally allocated between the supplier and the retailer. Under VMI compared to RMI, it is seen that costs incurred by the supplier and benefits to the retailer decrease as shipment cost changes from low level to high level. The retailer becomes worse-off in majority of the test instances because increase in cost of carrying on-site stock is greater than transfer of order issuing costs. For example, moving from Sst $=0$ to Sst $=1500$, while cost saving of the retailer reduces from 67.56 to $-212.11 \%$, the VMI results in increase in cost savings of the supplier from -9.57 to 
26.95\%. Thus, the supplier needs to reduce unit price and/or consign the inventory in order to make VMI a viable option for the retailer when shipment cost is large.

\section{Managerial insights}

The results of this study are of practical importance to managers. Our study shows that improvement in supply chain performance measures due to shift in inventory ownership or shift in decision-making power beyond IS is substantially influenced by business environment in which partners work. There exist complex interactions among a large number of system parameters. Thereby, an analytical model-based decision support is required to analyse and quantify the exact improvements which RMCl or VMI may provide beyond and above IS to the partners. Such an analysis helps the partners to decide whether to switch beyond IS or not. This study has been carried out taking into account these aspects and would certainly help the managers in taking right decisions to some extent.

Our experimental results exhibit that the retailer always gains by moving from RMI to RMCI. The cost savings of the retailer under $\mathrm{RMCl}$ increase as ordering cost and the variability of demand increase. The retailer, however, needs to allocate more stocking space as average on-site inventory increases under $\mathrm{RMCl}$ due to increase in replenishment sizes. We observe that supplier may or may not gain by moving from RMI to RMCl. The shift in inventory ownership can be a viable option for the supplier when setup and shipment costs of the supplier are sufficiently high.

Moreover, order issuing cost and inventory holding cost of the retailer as well as opportunity cost component of carrying inventory should be such that the retailer prefers frequent small size orders under RMI; on the contrary, he/she would demand significantly larger quantities under $\mathrm{RMCl}$. Thus, system-wide inventory under $\mathrm{RMCl}$ is usually higher than RMI, but economic benefits can be achieved when reduction in setup, ordering and shipment-related expenses are greater than cost incurred to carry increased inventory. For given demand pattern, $\mathrm{RMCl}$ would be more attractive when demand variability is large.

It is observed that beyond IS, the shift in decision-making power provides significantly higher system-wide benefits in terms of cost reduction than shift in inventory ownership. For example, while the shift in inventory ownership reduces cost incurred by system as a whole by $1.33 \%$ on average, the system-wide cost saving across problem sets is $11.4 \%$ under VMI. We observe that system-wide cost benefits accrued from the shift in decision-making power beyond IS are greater particularly when product, for which VMI strategy is adopted, has less variability in demand pattern and high shipment cost. Even more, benefits further increase as order issuing efficiency factor and timedependent variation in production cost increase.

The inventory level at the retailer may or may not decrease under VMI as compared to RMI. If the retailer orders more frequently under the RMI and the supplier replenishes less frequently under VMI then the inventory level at the retailer increases under VMI. In such a situation, the retailer may become worse-off under VMI if cost incurred to carry additional stock is more than transfer of order issuing costs as a result of shift in decision-making power. If this is the case, the supplier has to decrease unit price and/or consign the stock so that the retailer may not remain worse-off under VMI as compared to RMI. The increase in the supplier's ordering efficiency factor is also advantageous to the retailer. Under VMI, we observe that inventory levels at the retailer decrease with increase in ordering efficiency of the supplier due to increase in replenishment frequency or decline in shipment sizes. Across all the problem settings, increasing $\beta$ by $40 \%$ reduces inventory carrying expenses by $13.63 \%$.

It is seen from experimental results that inventory levels at the supplier decrease under VMI in a majority of the test instances. However, VMI may not be attractive for the supplier when additional cost burden of shift in order issuing cost is higher than decline in inventory- and production-related costs. The cost incurred by the supplier is large under VMI than RMI when order issuing cost is at high level and efficiency factor is at low level. This observation suggests that order issuing cost is not to be transferred completely to the supplier under VMI particularly when shipment cost is negligible; but, it is to be judiciously shared between both the partners for VMI to work under deterministic timevarying demand conditions. 


\section{Conclusions, limitations and directions for future research}

The increased cost pressure and more demanding customers have forced the companies to move ahead of IS to improve supply chain competitiveness with new form of retailer-supplier collaborative initiatives such as shift in inventory ownership and/or shift in decision-making power. This study applies integer linear programming models to quantify benefits that can be accrued with shift in inventory ownership (RMCl) or shift in decision-making power (VMI) beyond IS (RMI) for a retailer, a supplier and system as a whole under deterministic time-varying demand conditions. We aim to figure out when benefits of $\mathrm{RMCl}$ or $\mathrm{VMI}$ are significantly greater than RMI. In practice, higher level of collaboration between the supplier and the retailer leads to greater implementation difficulties and increase in operational costs. In other words, benefits of increased level of collaboration must compensate the cost of investing in that particular initiative. Thus, our study would help managers of a supply chain to determine an appropriate RSP according to their specific business environment.

The results of a detailed numerical study suggest that $\mathrm{RMCl}$ provides system-wide cost benefits in specific settings; particularly, when the shift in inventory ownership induces the retailer's to place larger order quantities and the supplier also prefers such orders due to significantly high setup and shipment costs. On the contrary, the relative benefits of shift in decision-making power are always higher than shift in inventory ownership under all the conditions considered in this study. However, when the shipment cost is negligible and/or order issuing efficiency factor of the supplier is low, the cost benefits of switching from RMI to VMI are not significant. In such a situation, the decision of switching from RMI to VMI is not justifiable when we consider the implementation difficulties and additional resources required for VMI adaptation.

The results also indicate that the value of VMI is substantially greater than IS under the conditions where shipment cost is high and retailer places small size quantities frequently under RMI. However, under such a situation, moving from IS to shift in decision-making power benefits only the supplier. More precisely, the retailer may not join VMI as its on-site stock increases significantly if storage space is a constraint or supplier is not ready to compensate the retailer's losses by providing quantity discounts. We observe that moving from RMI to VMI not only provides substantial gain, but also benefits to both the retailer and supplier almost on an equal basis when the cost parameters take moderate values.

We observe that cost savings under $\mathrm{RMCl}$ increase, but deteriorate under VMI as variability of demand increases. On the other hand, the cost benefits under $\mathrm{RMCl}$ decrease, but increase under $\mathrm{VMI}$ as randomness of production cost increases. Thus, indicating that lower variability of demand and highly variable production cost result in improvement in performance measures under VMI. On the other hand, higher variability of demand and stable production cost lead to higher benefits under $\mathrm{RMCl}$. This indicates that the gap between the cost benefits produced by VMI compared to $\mathrm{RMCl}$ narrows down as the variability of underlying demand increases and/or time-dependent variations in the variable production cost decrease.

Our results and managerial insights are based on a detailed numerical study under specific problem assumptions and parameter settings. Additional research, based on data drawn from different business environment, is worthwhile. A study investigating the impact of non-stationary setup and order issuing cost structures or operational constraints, such as production capacity and inventory storage limitations on performance measures seems well justified. The research may be further extended considering CPFR partnership. The impacts of demand management through promotions and forward buying can be evaluated on supply chain performance measures by comparing CPFR with VMI. Also, the analysis carried out in the current study could be extended towards stochastic time-varying demand conditions. These extensions have not been addressed so far in the literature.

Notes

R: the retailer, S: the supplier, Y: yes, N: no, L: low, M: medium, H: high.

Source: Simchi-Levi et al. (2008), Gümüş, Jewkes, and Bookbinder (2008), Tyan and Wee (2003). 
References

1. Achabal, D., S. H. Mcintyre, S. A. Smith, and K. Kalyanam. 2000. "A Decision Support System for Vendor Managed Inventory." Journal of Retailing 76 (4): 430-454.10.1016/S0022-4359(00)00037-3

2. Archetti, C., L. Bertazzi, G. Laporte, and M. G. Speranza. 2007. "A Branch-and-cut Algorithm for a Vendor-managed Inventory-routing Problem." Transportation Science 41 (3): 382-391.10.1287/trsc.1060.0188

3. Aviv, Yossi. 2002. "Gaining Benefits from Joint Forecasting and Replenishment Processes: The Case of Auto-correlated Demand." Manufacturing \& Service Operations Management 4 (1): 55-74.10.1287/msom.4.1.55.285

4. Barratt, M. 2004. "Understanding the Meaning of Collaboration in the Supply Chain." Supply Chain Management: an International Journal 9 (1): 30-42.10.1108/13598540410517566

5. Barratt, M., and A. Oliveira. 2001. "Exploring the Experiences of Collaborative Planning Initiatives." International Journal of Physical Distribution \& Logistics Management 31 (4): 266-289.

6. Battini, D., A. Grassi, A. Persona, and F. Sgarbossa. 2010. "Consignment Stock Inventory Policy: Methodological Framework and Model." International Journal of Production Research 48 (7): 2055-2079.10.1080/00207540802570669

7. Battini, D., A. Gunasekaran, M. Faccio, A. Persona, and F. Sgarbossa. 2010. “Consignment Stock Inventory Model in an Integrated Supply Chain." International Journal of Production Research 48 (2): 477-500.10.1080/00207540903174981

8. Ben-Daya, M., E. Hassini, M. Hariga, and M. M. AlDurgam. 2013. "Consignment and Vendor Managed Inventory in Single-vendor Multiple Buyers Supply Chains." International Journal of Production Research 51 (5): 1347-1365.10.1080/00207543.2012.662725

9. Bookbinder, J. H., M. Gümüş, and E. M. Jewkes. 2010. "Calculating the Benefits of Vendor Managed Inventory in a Manufacturerretailer System." International Journal of Production Research 48 (19): 5549-5571.10.1080/00207540903095434

10. Borade, A. B., G. Kannan, and S. V. Bansod. 2013. "Analytical Hierarchy Process-based Framework for VMI Adoption." International Journal of Production Research 51 (4): 963-978.10.1080/00207543.2011.650795

11. Braglia, M., and L. Zavanella. 2003. "Modelling an Industrial Strategy for Inventory Management in Supply Chains: The 'Consignment Stock' Case." International Journal of Production Research 41 (16): 3793-3808.10.1080/0020754031000138330

12. Cachon, G. P. 1999. Stock Wars: Inventory Competition in a Two-echelon Supply Chain with Multiple Retailers. Working Paper. Durham, NC: Fuqua School of Business, Duke University.

13. Chen, L.-T., and C.-C. Wei. 2012. "Multi-period Channel Coordination in Vendor-managed Inventory for Deteriorating Goods." International Journal of Production Research 50 (16): 4396-4413.10.1080/00207543.2011.592159

14. Choi, K.-S., J. G. Dai, and J. S. Song. 2004. "On Measuring Supplier Performance under Vendor-managed-inventory Programs in Capacitated Supply Chains." Manufacturing \& Service Operations Management 6 (1): 53-72.10.1287/msom.1030.0029

15. Choi, T.-M., and S. Sethi. 2010. "Innovative Quick Response Programs: A Review." International Journal of Production Economics 127: 1-12.10.1016/j.ijpe.2010.05.010

16. Choudhary, D., and R. Shankar. 2011. "Modeling and Analysis of Single Item Multi-period Procurement Lot-sizing Problem Considering Rejections and Late Deliveries." Computers \& Industrial Engineering 61: 1318-1323.

17. Corbett, C. J. 2001. "Stochastic Inventory Systems in a Supply Chain with Asymmetric Information: Cycle Stocks, Safety Stocks, and Consignment Stock." Operations Research 49 (4): 487-500.10.1287/opre.49.4.487.11223

18. Dong, Y., and K. Xu. 2002. "A Supply Chain Model of Vendor Managed Inventory." Transportation Research Part E: Logistics and Transportation Review 38: 75-95.10.1016/S1366-5545(01)00014-X

19. Fang, X., K. C. So, and Y. Wang. 2008. "Component Procurement Strategies in Decentralized Assemble-to-order Systems with Timedependent Pricing." Management Science 54 (12): 1997-2011.10.1287/mnsc.1080.0934

20. Fry, M. J., R. Kapuscinski, and T. L. Olsen. 2001. "Coordinating Production and Delivery under a (Z, Z)-type Vendor-managed Inventory Contract." Manufacturing \& Service Operations Management 3 (2): 151-173.10.1287/msom.3.2.151.9989

21. Gavirneni, S., R. Kapuscinski, and S. Tayur. 1999. "Value of Information in Capacitated Supply Chains." Management Science 45 (1): 1624.10.1287/mnsc.45.1.16

22. Giunipero, L. C., S. S. Fiorito, D. H. Pearcy, and L. Dandeo. 2001. "The Impact of Vendor Incentives on Quick Response." The International Review of Retail, Distribution and Consumer Research 11 (4): 359-376.

23. Gümüş, M., E. M. Jewkes, and J. H. Bookbinder. 2008. "Impact of Consignment Inventory and Vendor-managed Inventory for a Twoparty Supply Chain." International Journal of Production Economics 113: 502-517.10.1016/j.ijpe.2007.10.019

24. Hariga, M. A., and A. Al-Ahmari. 2013. "An Integrated Retail Space Allocation and Lot-sizing Models under Vendor Managed Inventory and Consignment Stock Arrangements." Computers \& Industrial Engineering 64: 45-55.

25. Hariga, M., M. Gumus, A. Daghfous, and S. K. Goyal. 2013. "A Vendor Managed Inventory Model under Contractual Storage Agreement." Computers \& Operations Research 40: 2138-2144.

26. Jans, R., and Z. Degraeve. 2008. "Modeling Industrial Lot Sizing Problems: A Review." International Journal of Production Research 46 (6): 1619-1643.10.1080/00207540600902262

27. Jaruphongsa, W., S. Çetinkaya, and C.-Y. Lee. 2004. "A Two-echelon Inventory Optimization Model with Demand Time Window Considerations." Journal of Global Optimization 30: 347-366.10.1007/s10898-004-6092-y

28. Kannan, G. 2013. "Vendor-managed Inventory: A Review Based on Dimensions." International Journal of Production Research 51 (13): 3808-3835. 
29. Kannan, G., M. C. Grigore, K. Devika, and A. Senthilkumar. 2013. "An Analysis of the General Benefits of a Centralised VMI System Based on the EOQ Model." International Journal of Production Research 51 (1): 172-188.10.1080/00207543.2011.653838

30. Lee, J.-Y., and L. Ren. 2011. "Vendor-managed Inventory in a Global Environment with Exchange Rate Uncertainty." International Journal of Production Economics 130: 169-174.10.1016/j.ijpe.2010.12.006

31. Lee, H. L., K. C. So, and C. S. Tang. 2000. "The Value of Information Sharing in a Two-level Supply Chain." Management Science 46 (5): 626-643.10.1287/mnsc.46.5.626.12047

32. Lee, W., and S.-P. Wang. 2008. "Managing Level of Consigned Inventory with Buyer's Warehouse Capacity Constraint." Production Planning \& Control 19 (7): 677-685.10.1080/09537280802573627

33. Li, S., Z. Zhu, and L. Huang. 2009. "Supply Chain Coordination and Decision Making under Consignment Contract with Revenue Sharing." International Journal of Production Economics 120: 88-99.10.1016/j.ijpe.2008.07.015

34. Marquès, G., C. Thierry, J. Lamothe, and D. Gourc. 2010. "A Review of Vendor Managed Inventory (VMI): From Concept to Processes." Production Planning \& Control 21 (6): 547-561.10.1080/09537287.2010.488937

35. Pasandideh, S. H. R., S. T. A. Niaki, and A. R. Nia. 2010. "An Investigation of Vendor-managed Inventory Application in Supply Chain: the EOQ Model with Shortage." The International Journal of Advanced Manufacturing Technology 49: 329-339.10.1007/s00170-009-23645

36. Persona, A., A. Grassi, and M. Catena. 2005. "Consignment Stock of Inventories in the Presence of Obsolescence." International Journal of Production Research 43 (23): 4969-4988.10.1080/00207540500216631

37. Razmi, J., R. H. Rad, and M. S. Sangari. 2010. “Developing a Two-echelon Mathematical Model for a Vendor-managed Inventory (VMI) System." The International Journal of Advanced Manufacturing Technology 48: 773-783.10.1007/s00170-009-2301-7

38. Ru, J., and Y. Wang. 2010. "Consignment Contracting: Who Should Control Inventory in the Supply Chain?" European Journal of Operational Research 201: 760-769.10.1016/j.ejor.2009.04.006

39. Sahin, F., and E. P. Robinsonjr. 2005. "Information Sharing and Coordination in Make-to-order Supply Chains." Journal of Operations Management 23: 579-598.10.1016/j.jom.2004.08.007

40. Savaşaneril, S., and N. Erkip. 2010. "An Analysis of Manufacturer Benefits under Vendor-managed Systems." IIE Transactions 42 (7): 455-477.10.1080/07408170903459968

41. Simchi-Levi, D., P. Kaminsky, E. Simchi-Levi, and R. Shankar. 2008. Designing and Managing the Supply Chain: Concepts, Strategies, and Case Studies. 3rd ed. New Delhi: Tata McGraw-Hill.

42. Solyali, O., and H. Süral. 2008. "A Single Supplier-Single Retailer System with an Order-up-to Level Inventory Policy." Operations Research Letters 36: 543-546.10.1016/j.orl.2008.05.005

43. Toktaş-Palut, P., and F. Ülengin. 2011. "Coordination in a Two-stage Capacitated Supply Chain with Multiple Suppliers." European Journal of Operational Research 212: 43-53.10.1016/j.ejor.2011.01.018

44. Tyan, J., and H.-M. Wee. 2003. "Vendor Managed Inventory: A Survey of the Taiwanese Grocery Industry." Journal of Purchasing \& Supply Management 9: 11-18.

45. Valentini, G., and L. Zavanella. 2003. "The Consignment Stock of Inventories: Industrial Case and Performance Analysis." International Journal of Production Economics 81-82: 215-224.10.1016/S0925-5273(02)00300-6

46. van der Vlist, P., R. Kuik, and B. Verheijen. 2007. "Note on Supply Chain Integration in Vendor-managed Inventory." Decision Support Systems 44: 360-365.10.1016/j.dss.2007.03.003

47. Wagner, H. M., and T. M. Whitin. 1958. “Dynamic Version of the Economic Lot-size Model." Management Science 5: 89$96.10 .1287 / \mathrm{mnsc} .5 .1 .89$

48. Xu, K., and M. T. Leung. 2009. "Stocking Policy in a Two-party Vendor Managed Channel with Space Restrictions." International Journal of Production Economics 117: 271-285.10.1016/j.ijpe.2008.11.003

49. Yao, Y., and M. Dresner. 2008. "The Inventory Value of Information Sharing, Continuous Replenishment, and Vendor-managed Inventory." Transportation Research Part E: Logistics and Transportation Review 44: 361-378.10.1016/j.tre.2006.12.001

50. Yao, Y., P. T. Evers, and M. E. Dresner. 2007. “Supply Chain Integration in Vendor-managed Inventory." Decision Support Systems 43: 663-674.10.1016/j.dss.2005.05.021

51. Zanoni, S., M. Y. Jaber, and L. E. Zavanella. 2012. "Vendor Managed Inventory (VMI) with Consignment Considering Learning and Forgetting Effects." International Journal of Production Economics 140 (2): 721-730.10.1016/j.ijpe.2011.08.018

52. Zavanella, L., and S. Zanoni. 2009. “A One-vendor Multi-buyer Integrated Production-inventory Model: the 'Consignment stock' Case.” International Journal of Production Economics 118: 225-232.10.1016/j.ijpe.2008.08.044 